\title{
A ATUAÇÃO NO PELC/UFSM E A FORMAÇÃO EXPERIENCIAL DOS EDUCADORES SOCIAIS DE ESPORTE E LAZER
}

Recebido em: 14/08/2013

Aceito em: 07/02/2014

\author{
Felipe Barroso de Castro ${ }^{1}$ \\ Maria Cecília Camargo Günther ${ }^{2}$ \\ Universidade Federal de Santa Maria \\ Santa Maria - RS - Brasil \\ Elisandro Schultz Wittizorecki ${ }^{3}$ \\ Universidade Federal do Rio Grande do Sul \\ Porto Alegre - RS - Brasil
}

RESUMO: Pretendemos com esse estudo realizar uma primeira aproximação com nosso tema central de pesquisa: a formação experiencial de educadores sociais de esporte e lazer a partir da atuação no Programa Esporte e Lazer da Cidade da Universidade Federal de Santa Maria (PELC/UFSM). Buscamos, a partir disso, identificar e compreender de que modo a atuação nesse Programa vem repercutindo sobre a formação experiencial desses educadores sociais. Trata-se de uma pesquisa exploratória, realizando primeiramente a análise de alguns documentos e, em um segundo momento, a aplicação de um questionário com o grupo de colaboradores. Consideramos previamente que a experiência de atuação contribuiu para a formação de identidades caracterizadas a partir de um perfil desse educador social de esporte e lazer, bem como da compreensão e apropriação de seu papel educativo, quando inserido na realidade das comunidades.

PALAVRAS CHAVE: Docentes. Esportes. Atividades de Lazer.

\section{THE ACTING IN THE PELC/UFSM AND THE EXPERIENCE FORMATION OF EDUCATORS SOCIAL OF SPORTS AND LEISURE}

ABSTRACT: We intend to make this study a first approximation in relation to our central research topic, experiential formation of educators social of sport and leisure from of the acting in the Programa Esporte e Lazer da Cidade of Universidade Federal

\footnotetext{
${ }^{1}$ Mestrando em Educação Física do Centro de Educação Física e Desportos da Universidade Federal de Santa Maria (CEFD/UFSM).

${ }^{2}$ Professora Adjunta do Departamento de Desportos Individuais (DDI) do Centro de Educação Física e Desportos da Universidade Federal de Santa Maria (CEFD/UFSM).

${ }^{3}$ Professor Adjunto do Departamento de Educação Física da Escola de Educação Física e no Programa de Pós-Graduação em Ciências do Movimento Humano da Universidade Federal do Rio Grande do Sul.
} 
de Santa Maria (PELC/UFSM). We seek, from that, to identify and understand how the acting in this program comes reverberating about formation experience of these social educators. We treat this work as an exploratory study, performing primarily an analysis of some documents and in a second moment the application to a questionnaire with the group of collaborators. We consider, beforehand, that the experience of the acting contributed to the formation of identities characterized from a profile of this social educator of sport and leisure, as well as the understanding and ownership of their educative role, when inserted into the reality of the communities.

KEYWORDS: Sports. Leisure Activities. Faculty.

\section{Introdução}

Este estudo faz parte de um projeto mais amplo ${ }^{4}$ que se propõe a investigar os percursos que os acadêmicos vêm trilhando ao longo da graduação nos cursos de Educação física do CEFD/UFSM, bem como a problemática central de como o envolvimento desses estudantes nas mais variadas atividades extracurriculares vem repercutindo sobre seus processos formativos.

Nessa direção, o presente estudo surgiu inicialmente para investigar um projeto de extensão específico (PELC/UFSM), no qual as atividades de lazer são o eixo central do Programa. A escolha do PELC/UFSM como espaço formativo e de intervenção a ser investigado surge primeiramente a partir das experiências de um dos autores desse trabalho. Essas experiências foram desde a intervenção direta nas realidades sociais, enquanto educador social de esporte e $1 \mathrm{azer}^{5}$, até um trabalho de gestão como coordenador de núcleo do Programa.

Observamos durante os cursos de formação do PELC relatos de alguns acadêmicos (educadores sociais) que expressavam um pouco do cotidiano da atuação nas comunidades. Nesses relatos, eram expostos desafios encontrados, relações de troca

\footnotetext{
${ }^{4} \mathrm{O}$ nome do referido projeto foi suprimido com o intuito de manter preservada a identificação do mesmo e também dos autores deste manuscrito.

${ }^{5}$ Denominação realizada por Tondin (2011) quando se refere aos agentes sociais de esporte e lazer do PELC. Mais adiante nesse trabalho, explicamos o porquê concordamos e optamos por essa nomenclatura.
} 
de conhecimentos com lideranças comunitárias, processos de lutas sociais e mobilizações, enfim, um conjunto de elementos que nos possibilitou refletir sobre as potencialidades formativas da experiência de atuação no Programa.

A partir disso, propusemo-nos a pensar sobre o que essa experiência de atuação poderia estar colaborando ou não para a formação desses educadores sociais. Nessa perspectiva, formulamos a questão norteadora desse estudo da seguinte maneira: De que modo a atuação no Programa vem repercutindo sobre o processo de formação experiencial desses educadores?

Configuramos essa investigação como uma pesquisa exploratória na tentativa de ampliarmos os conhecimentos a respeito de nosso tema (formação experiencial dos educadores sociais). Primeiramente, realizamos uma análise sobre alguns documentos do PELC e, em um segundo momento, aplicamos um questionário aberto a nosso grupo de colaboradores.

\section{Formação e atuação profissional no lazer: os educadores sociais do PELC/UFSM}

O lazer como campo de estudo e atuação multidisciplinar teve a partir das décadas de 1970 e 1980 um salto quantitativo e qualitativo de produções acadêmicas, preocupadas em avançar a discussão do tema no país. Dentre outros fatores, a organização de grupos de pesquisa e a realização de eventos científicos sobre lazer contribuíram para que o tema emergisse para um debate mais consolidado no meio acadêmico em um cenário social onde se destaca a mercadorização na indústria do lazer e do entretenimento (GOMES e MELO, 2003).

Somado a isso, percebe-se a partir do início da última década uma maior iniciativa governamental relacionada às práticas de lazer, em especial as de caráter 
físico-esportivas a partir de programas sociais. Um breve olhar na página eletrônica do Ministério do Esporte (ME) já é o suficiente para constatarmos essa preocupação do governo federal brasileiro e seus Programas: Segundo Tempo, Bolsa Atleta, Descoberta do Talento Esportivo, além do próprio Programa Esporte e Lazer da Cidade (PELC) ${ }^{6}$.

Tondin (2011), ao analisar a Política Nacional do Esporte (BRASIL, 2005), descreve que o ME parece estar preocupado em democratizar o acesso às práticas de esporte e lazer para a população em geral, tratando-os com um bem cultural importantes para a construção da cidadania e do desenvolvimento humano e social. Dessa forma, segue o autor, o ME pretende tratar e direcionar o esporte e o lazer como políticas sociais, evidenciando suas pretensões ao eleger a inclusão social como núcleo central das suas ações.

O entendimento dos processos de inclusão e exclusão social torna-se fundamental para a compreensão geral das políticas de esporte e lazer no país, em especial o PELC. Thomassim (2007), preocupado em discutir os sentidos da exclusão social na área da educação física, considera duas principais concepções relacionadas ao tema. Uma delas trata a exclusão social como uma condição, ou seja, ela condiciona os conflitos sociais existentes. Já a outra concepção considera a exclusão social como um processo social, resultado da forma como nossa sociedade (capitalista) está estruturada e organizada. Nessa última perspectiva, as condições de exclusão não se explicam em si, mas como produto de processos sociais que estão acontecendo.

\footnotetext{
${ }^{6}$ O Programa foi criado no ano de 2003 e é proveniente de uma ação governamental que integra uma política de esporte e lazer do tipo finalístico, justificando sua existência, ainda hoje, pela desigualdade de acesso ao esporte e lazer por parcela significativa da população brasileira. Seus objetivos centrais compreendem a ampliação, democratização e universalização do acesso as práticas de lazer, incentivando esses momentos e visando a inclusão social e a auto organização comunitária (disponível em: http://www.esporte.gov.br/sndel/esporteLazer/default.jsp, acesso em 11 de julho de 2011).
} 
Nesse viés, Mascarenhas (2005) descreve que, no Brasil, ao longo do seu processo histórico recente, as desigualdades sociais e a exclusão social vêm sofrendo um processo de naturalização. Segundo o autor, "o lazer assume a condição de um nãodireito, manifestando-se como objeto de conquista no mercado" (MASCARENHAS, 2005, p. 7) [grifo do autor] o que dá margem para uma situação de profunda desigualdade de acesso. Se por um lado existem os ricos, considerados os com-lazer, usufruindo de tudo o que há de melhor disponível no mercado, por outro existem os de classe média, que na maioria das vezes se endividam para conseguir o acesso ao lazer de segunda-mão; e os pobres, quase sem ou sem-lazer que correspondem a maioria da população (MASCARENHAS, 2005).

Em meio a essa desigualdade e em substituição à universalização dos direitos, “as políticas passam a pautar-se pela lógica focalista, com a introdução de compensações pontuais visando o funcionamento do sistema e a conservação da ordem institucional" (MASCARENHAS, 2005, p. 8) [grifo do autor]. Nessa perspectiva, as políticas governamentais buscam o combate à exclusão social a partir do incentivo a participação popular, com especial atenção às camadas periféricas das grandes e médias cidades, em projetos culturais, educativos e de lazer.

Percebemos que o tema da inclusão social está diretamente relacionado à exclusão social, pois, se consideramos a possibilidade de alguém socialmente incluído, é porque também há a possibilidade deste alguém estar excluído. Segundo Taffarel (2009), a relação inclusão/exclusão social precisa ser compreendida como um par dialético, devendo ser analisada em conjunto e não isoladamente por um dos pólos (incluir ou excluir). Para a autora, não há possibilidade de inclusão em um sistema cuja base estrutural está pautada pela exploração humana. O que parece haver então são 
novas formas de inclusão/exclusão social caracterizadas por uma segregação inclusiva ou uma exclusão includente (TAFFAREL, 2009).

Essas novas formas de inclusão/exclusão social, citadas pela autora, são formas de aparente mudança situacional dos sujeitos nos mais diversos espaços sociais (educacional, de lazer, etc). Entretanto, cientes das considerações da autora (TAFFAREL, 2009), acreditamos, em consonância com Thomassim (2007), que "exclusão e inclusão podem ser compreendidas também como categorias do campo, ou seja, como representação de um sujeito social que, embora receptor e reprodutor de um discurso dominante, não é incondicionalmente dominado por este" (THOMASSIM, 2007, p. 172 e 173).

Nessa perspectiva, Thomassim (2007, p. 166) descreve que quando consideramos "a individualização da exclusão ela deixa de ser uma representação das relações sociais para apresentar-se como a própria realidade, como objeto real e não mais como discurso sobre o real". Ao analisar um dos estudos de Mascarenhas (2004), o autor cita um exemplo ao tratar do discurso sobre uma parcela dos jovens sem-lazer,

\begin{abstract}
Vendo um jovem pobre em estado de não-lazer, cercado pelas limitações materiais de acesso ao lazer, pode-se mesmo supor: eis um sem-lazer. Ao passo que imaginamos sua vida de sem-lazer, independente de que sejam conhecidos seus hábitos, suas práticas e táticas e, até mesmo, suas próprias representações sobre o lazer. Somos levados a desconsiderar seu estatuto de sujeito e principalmente, que a expressão sem-lazer não significa outra coisa que a representação de dados estatísticos que indicam a precariedade de acesso ao lazer (THOMASSIM, 2007, 167).
\end{abstract}

A premissa da inclusão social ganha destaque dentro dos Programas sociais que objetivam a democratização do acesso às práticas de lazer no Brasil. Compreendemos as limitações desses Programas quando atentamos para suas vigências temporárias e passageiras, somadas a uma política de lazer por parte do governo federal que busca 
uma inclusão social muito mais semelhante às ações de uma integração ou inserção social propriamente, dadas as condições sociais de desigualdade em que vivemos.

$\mathrm{Na}$ tentativa de suprir, mesmo que de modo limitado, com essa demanda principal, Programas sociais como o PELC são desenvolvidos no país. Desde o ano de 2010, a Universidade Federal de Santa Maria (UFSM) mantém uma parceria com o ME, a partir do PELC/UFSM Todas as idades. Essa nomenclatura justifica-se a partir de ações de intergeracionalidade, característica marcante no Programa que compreende as possibilidades de inserção e participação de pessoas de diferentes faixas etárias dentro de um mesmo espaço de aula, oficina pedagógica, evento de esporte e lazer, entre outras intervenções na comunidade. O Programa atende várias regiões da cidade, levando até as comunidades momentos de lazer desenvolvidos, sistematicamente, a partir de aulas em espaços públicos e/ou privados (escolas, igrejas, centros comunitários, praças públicas, etc), sempre de maneira gratuita.

Conforme consta no documento do Projeto Básico do PELC/UFSM (BRASIL, 2010), o Programa visa proporcionar à comunidade o acesso ao esporte e ao lazer como forma de desenvolvimento social, orientando-a em um processo de formação do cidadão em seu sentido mais amplo, voltado à participação popular e a auto-organização comunitária. A relação de aproximação da Universidade com as realidades sociais propicia a inserção dos conhecimentos acadêmicos na comunidade tornando-a um

[...] laboratório de práticas pedagógicas, difusor de ideias, reflexões e ações no sentido de direcionar a comunidade ao desenvolvimento social, a autonomia, a cidadania e que assim possam contribuir para elaboração de uma sociedade mais consciente da importância de sua participação social (BRASIL, 2010, p. 4).

Os acadêmicos de Educação Física que atuam no Programa (agentes sociais de esporte e lazer como são denominados pelo ME) são os mediadores desse processo, sendo os sujeitos que realizam as intervenções nas comunidades e que estabelecem as 
relações de maior proximidade com os membros de cada comunidade. Sistematicamente, eles possuem suas atribuições previstas nas Diretrizes - Emendas Parlamentares - do PELC (BRASIL, 2012). São elas:

1. Participar das ações de planejamento, monitoramento e avaliação das atividades sistemáticas e eventos do Núcleo; 2. Planejar e desenvolver suas oficinas de acordo com a proposta pedagógica do projeto; 3. Mobilizar a comunidade para a efetiva participação das atividades; 4. Inscrever e monitorar a participação nas atividades sob sua responsabilidade; 5 . Participar das ações de Formação Continuada; 6. Entregar sistematicamente o levantamento das atividades desenvolvidas no Núcleo e os dados solicitados pela coordenação (BRASIL, 2012, p. 15).

As atribuições desses “agentes sociais de esporte e lazer", quando contempladas, demonstram o envolvimento dos mesmos com o Programa, e consequentemente com a(s) comunidade(s) onde atuam. A experiência de um dos autores deste trabalho, enquanto atuante no Programa, aponta para esta perspectiva quando, em suas intervenções nas comunidades, vivenciava a rotina de uma determinada realidade local. O tempo de atuação semanal, assim como o tempo total de um ano da vigência do Programa, proporcionou um processo de inserção na comunidade ao ponto deste sujeito sentir-se como parte constituinte dela, lançando seu olhar sobre os problemas sociais que permeavam a realidade cotidiana daquelas pessoas, assim como compreendendo as relações de desigualdades sociais existentes.

Segundo o estudo de Ewerton (2010), percebe-se, estabelecida pelas diretrizes do Programa e seguida pelos agentes sociais, uma filosofia na qual os mesmos entendem suas intervenções pedagógicas enquanto dimensão social da formação humana. Nessa direção, complementa a autora que

[...] o 'saber fazer' parte de uma reflexão crítica, e o 'saber ser' parte da sabedoria exercitada. Nessa perspectiva a função dos agentes é criar as possibilidades para a produção e construção de conhecimentos junto à comunidade, e não apenas transferir conhecimentos já formulados (EWERTON, 2010, p.77). 
Consideramos, tendo em vista o cumprimento das suas atribuições, que o aparente envolvimento dos agentes sociais com as atividades do PELC/UFSM vai ao encontro das considerações da autora. Além disso, as ações desenvolvidas por esses agentes parecem ultrapassar o que se preconiza para esse papel profissional (agente social de esporte e lazer). Em vista disso, acreditamos que, em consonância com Tondin (2011), eles são educadores sociais de esporte e lazer [grifo nosso], pois, segundo o autor baseado nas concepções de Figueiredo, P. O. F. N (2009), ocupam o papel de mediadores na relação educador/aluno, ressignificando-a a partir de uma prática pedagógica reflexiva.

Nessa perspectiva, os educadores procuram romper com a lógica da racionalidade técnica, superando as características provenientes de um fazer instrucional, próprio do que se costuma denominar de "tarefismo". Ao assumirem o seu papel político, esses educadores sociais "tem a possibilidade de protagonizar momentos de mudanças, em uma nova relação social entre os sujeitos" (TONDIN, 2011, p. 46), sobretudo no que diz respeito aos processos de conscientização social.

Na maioria dos PELCs do país, os educadores sociais que atuam no Programa não possuem obrigatoriamente formação acadêmica, pois, muitas vezes, são representantes comunitários com algumas vivências na área da educação física, artes, teatro, música, entre outras. No caso do PELC/UFSM, todos os educadores sociais devem possuir vínculo estudantil com a UFSM. Por esse motivo principal, segundo Figueiredo, P. O. F. N (2009), esses sujeitos, ao possuírem uma formação universitária na área pedagógica, concluída ou em andamento, são educadores sociais.

Para Isayama (2011), no Brasil, existem duas perspectivas de formação profissional para atuação no lazer. A primeira é pautada por uma lógica tecnicista, na 
qual a instrumentalização técnica e o domínio de procedimentos e metodologias são os fatores mais importantes no processo formativo dos profissionais do lazer. Nas palavras do autor, como resultante desses fatores, "reafirma-se a dicotomia teoria e prática, enfatizando-se a segunda e atribuindo menor importância às reflexões de cunho filosófico, político, cultural e sociológico, fundamentais no processo de atuação profissional nesse âmbito" (ISAYAMA, 2011, p. 94).

Em contraponto a essa lógica, a segunda perspectiva citada pelo autor diz respeito a uma formação centrada no conhecimento, na cultura e na crítica, preocupada com os processos educacionais para e pelo lazer. Dessa forma, busca superar a tendência tecnicista, bem como a dicotomia teoria e prática, tendo em vista uma práxis consciente. Nesse viés, o interessante é pensarmos na construção de saberes e competências necessárias para a materialização dessa perspectiva crítica de formação de educadores sociais de esporte e lazer.

No entanto, como trata Marcelino (1995), devemos ter certo cuidado, pois o discurso das competências profissionais também se faz presente na perspectiva tecnicista de formação para atuação no lazer. Segundo o autor, a crescente especialização do profissional de lazer acaba por fragmentar sua formação, havendo um direcionamento exagerado das atividades. Nessa perspectiva, "a 'especificidade concreta' do lazer exige um novo especialista, não o 'especialista tradicional' superficial e unidimensional - mas o que domine a sua especificidade dentro de uma visão de totalidade" (MARCELINO, 1995, p. 20 e 21).

Compreendemos que os saberes e competências desse "especialista crítico" precisam desenvolver-se dentro de uma perspectiva de formação profissional em que estes sujeitos estejam conscientes de seu papel social na educação para o lazer. Em 
outras palavras, precisam saber o que almejam com seu trabalho nas realidades onde atuam.

Além dessa consciência, Isayama (2009), considerando o profissional do lazer como um animador cultural; e Pinto (2001), considerando-o como educador para o lazer, descrevem que o comprometimento com os valores de uma sociedade democrática, o domínio dos conteúdos a serem socializados (sua contextualização e articulação interdisciplinar) e o domínio do conhecimento pedagógico são competências fundamentais que devem ser construídas concomitantemente com a formação crítica de um modo geral.

A formação dos educadores sociais de esporte e lazer do PELC é subsidiada por uma política formativa do próprio Programa, por meio da formação em serviço e dos cursos de formação que o mesmo proporciona. A formação em serviço propõe-se a um estudo da realidade, organização e aplicação do conhecimento trabalhado e avaliação contínua das ações. Isso inclui visitas aos locais das atividades, oficinas, relatos de experiências, trabalhos em grupos, produção e apresentação de artigos científicos, vídeo-conferência, grupos de estudos e reuniões pedagógicas semanais (BRASIL, 2010).

Já os cursos de formação acontecem em módulos sistematizados, divididos em três etapas. São elas:

\footnotetext{
Módulo I - Introdutório terá a duração de 32 horas no início da vigência do convênio e contará com a participação de formadores do Ministério do Esporte. Necessário se faz esclarecer que este módulo inicia-se com as diretrizes e objetivos do Programa Esporte e Lazer da Cidade para a formação de agentes que irão atuar no programa. Módulo II Aprofundamento conforme estrutura modular proposta pela SNDEL, que tem por objetivo aprofundar os conteúdos balizadores do Programa, bem como: Espaço de formação de novas lideranças comunitárias; Formação inicial dos acadêmicos de educação física; Formação de agentes comunitários como elos entre a comunidade e o PELC; Formação geral da sociedade no sentido de desenvolvimento social (educação geral da sociedade, não educação escolarizada, mas a formação da sociedade no sentido de utilizar os
} 
espaços onde acontece o PELC como espaços de formação de outras necessidades da população). Módulo III - Avaliação será dividida em duas etapas de 16 horas cada, uma no meio e a outra no final da vigência do convênio e contará com a participação de formadores do Ministério do Esporte. Além disso, realizaremos avaliações permanentes tais como: a cada aula, diagnósticos, reuniões entre os agentes sociais (BRASIL, 2010, p. 7) [grifos dos autores].

As ações formativas oferecidas pelo PELC vêm sendo tema de muitas investigações (EWERTON, 2010; FIGUEIREDO, P. O. F. N, 2009; SUASSUNA, 2009; TONDIN, 2010, 2011) evidenciando a importância destes espaços para o desenvolvimento do trabalho no Programa. O interessante aqui está em pensarmos que os processos formativos do PELC estão preocupados com uma formação que emerge da realidade do trabalho nas comunidades. Dessa forma, busca-se formar um educador social, entre outras características, consciente da importância de sua ação pedagógica relacionada aos objetivos do Programa.

Nessa perspectiva, Tondin (2011) descreve que a maneira como está organizada a formação no PELC acaba sendo uma possibilidade de formação continuada para os educadores, ocupando certa centralidade para a qualificação profissional destes. Ao pensar a relação formador do PELC e educador social, o autor destaca que a busca pela autonomia na atuação destes educadores pode ser considerada o ponto principal que as formações almejam, desde o módulo introdutório até os processos da formação em serviço. Nas palavras do autor,

Essa é a demanda premente do sujeito educador frente a uma situação inédita ou permeada de outras características que sugerem conflitos ou desafios. A intencionalidade do sujeito que organiza a aprendizagem na formação é a de buscar a reflexão sobre a prática do sujeito que a recebe, porque estão em papéis distintos, em momentos distintos de um mesmo processo (TONDIN, 2011, p. 82).

Nossa consideração nesse estudo é de que não somente os processos formativos do PELC, como também o envolvimento dos educadores sociais com todo o conjunto 
de atividades do Programa previstas em suas atribuições, já citadas neste trabalho, merecem uma maior atenção. O trabalho no PELC como um todo proporciona uma diversidade de vivências e conhecimentos que aqui iremos abordar como "aprendizagens experienciais", as quais protagonizam o processo de formação experiencial.

A seguir apresentamos uma breve explicação sobre esse processo na tentativa de relaciona-lo com a atuação dos educadores sociais no PELC.

\section{Possibilidades da formação experiencial}

A atuação do educador social de esporte e lazer no PELC caracteriza-se pela amplitude e diversidade de ações/atividades desenvolvidas ao longo do Programa. Cientes dessa característica, acreditamos na experiência dessa atuação como um processo de formação experiencial.

O termo experiência ao qual nos referimos não compreende os conceitos e significados do senso comum, tampouco do círculo vicioso e superficial da "experiência pela experiência". A experiência que tratamos aqui é mais profunda. A ela, ao serem atribuídos sentidos e significados, direciona-se um processo de autoformação, na qual os sujeitos formam-se a partir de suas experiências. Daí o termo "experiência formadora" (JOSSO, 2002) como um resultado sempre inacabado e por isso contínuo de aprendizagens experienciais.

Na explicação de Josso (2002), a aprendizagem experiencial fundamenta-se em conhecimentos que surgem a partir de vivências que simbolizam atitudes, comportamentos, pensamentos, saber-fazer e também sentimentos que caracterizam subjetividades e identidades. 
As experiências que são consideradas formadoras podem ser compreendidas como aprendizagens que articulam, hierarquicamente: saber-fazer e conhecimentos, funcionalidade e significação, técnicas e valores num espaço-tempo que oferece a cada um a oportunidade de uma presença para si e para a situação. As vivências que propiciam essas aprendizagens "atingem o status de experiências a partir do momento que fazemos certo trabalho reflexivo sobre o que se passou e sobre o que foi observado, percebido e sentido" (JOSSO, 2002, p. 48) [grifo da autora].

Josso (2002), ao ordenar três modalidades de elaboração construtivas da experiência formadora, destaca a modalidade "pensar sobre as experiências". Nesta modalidade, não há referência a uma experiência ou uma vivência em particular, mas sim a um conjunto de vivências que, ao serem sucessivamente trabalhadas tornam-se experiências.

Pensar sobre as experiências requer um trabalho reflexivo intenso, no qual não podemos negar a nós mesmos que possuímos uma trajetória baseada em nossas experiências sócio-culturais. Nessa direção, o exercício da reflexão pode realizar-se a partir da dialética entre o individual e o coletivo, ou seja, "de um lado, empenhamos a nossa interpretação (nos auto interpretamos) e, por outro, procuramos no diálogo com os outros uma co-interpretação da nossa experiência" (JOSSO, 2002, p. 54) [grifo da autora]. É a partir deste movimento dialético que nos formamos como humanos, em uma polaridade (eu e o outro), partilhando um destino comum devido ao fato de pertencermos juntos a uma comunidade.

As indagações que permeiam o "pensar sobre as experiências" e que constituem a experiência formadora, segundo a autora, nos chamam atenção quando nos questionamos: “mas no fundo o que é que se passou?", "fiz uma coisa diferente do que 
julgava fazer de início?”, “o que eu extraio como conhecimentos e saber-fazer do conjunto destas experiências?". Nessa direção, este trabalho reflexivo e de explicação para si mesmo do que foi experienciado progride na procura de uma simbolização que será discutida e negociada com os outros.

Os estudos que utilizam o conceito de experiência nas suas mais variadas manifestações (experiências docentes, formativas, histórias de vida, etc) não são novidade na área da educação. As relações com os saberes docentes e com a constituição da(s) identidade(s) ganham relevância nas pesquisas sobre formação de professores/educadores com esse viés (MOITA, 1992; NÓVOA, 1992; TARDIF, 2000). No âmbito da educação física, a experiência também vem ganhando espaço enquanto tema de pesquisas, como nos estudos de Figueiredo, Z. C. C (2004, 2009, 2010) e Almeida e Fensterseifer (2011).

Acreditamos que os saberes profissionais e a constituição da(s) identidade(s) desses educadores mantêm relações com as aprendizagens experienciais. Porém, não cabe aqui uma discussão muito aprofundada a esse respeito, tamanha sua amplitude e complexidade. Desse modo, embora reconheçamos a relevância e a indissociabilidade na relação experiência-identidade, nossas atenções estão mais voltadas sobre o processo de formação experiencial.

Sendo assim, retomando nossas considerações a respeito da formação experiencial, Moita (1992) discute a necessidade de entendermos como cada pessoa se forma, uma vez que um percurso de formação é também um processo de formação. Nesse sentido, Figueiredo, Z. C. C (2009) destaca uma perspectiva de formação para professores de educação física diretamente ligada com a experiência, o "formar-se" professor. Essa perspectiva situa o sujeito como sendo o próprio agente de sua 
formação. No entanto, o grande desafio está na compreensão de como as experiências pelas quais esse sujeito está envolvido estão sendo percebidas, principalmente no que diz respeito à atribuição de sentidos, significados e aprendizagens que estão sendo construídas nesse processo. Segundo a autora, a autoformação tem relação estreita com o pessoal e com a prática. Entretanto "ao contrário do que se possa pensar, ambos construídos do ponto de vista político e social e não do ponto de vista do indivíduo autônomo" (FIGUEIREDO, Z. C. C 2009, p. 5).

Partindo do pressuposto de que o processo formativo é inevitavelmente experiencial (JOSSO, 2002), a aproximação que pretendemos fazer aqui diz respeito a tratar a atuação no PELC em sua totalidade como uma experiência formadora, na busca de descobrir as possibilidades da formação destes educadores sociais não somente a partir do processo de formação continuada e dos cursos de formação do Programa, mas também da valorização de toda a experiência de atuação.

Esta totalidade a qual nos referimos compreende, além dos processos formativos do Programa, o trabalho cotidiano nas comunidades, no qual se destacam as aulas, as estratégias de divulgação das mesmas e os eventos de esporte e lazer. Ainda tratando dessas intervenções nas comunidades, acreditamos no diálogo e nas relações interpessoais estabelecidas com os sujeitos que compõem as comunidades. Dessas relações, surgem muitas histórias de vida, lutas sociais, mobilizações comunitárias, entre outras possibilidades de trocas de experiência e conhecimento.

\section{Opções metodológicas}

Para esse estudo, optamos por fazer uma primeira aproximação com os temas em questão, de modo que temos a consciência de que o assunto e o problema norteador 
dessa pesquisa não serão esgotados, dadas as limitações de um artigo científico. No entanto, buscamos ampliar os conhecimentos a respeito de nossa problemática para que possamos identificar aspectos relevantes e merecedores de uma análise mais aprofundada futuramente.

Nesta perspectiva, tratamos este trabalho como um estudo exploratório, pois, em concordância com Triviños (1987), partimos de uma hipótese na tentativa de aprofundar nossos estudos nos limites de uma realidade específica (a experiência de atuação no PELC), para, em seguida, a partir de nossas considerações prévias, apontar pistas que levem a estudos mais aprofundados em relação ao nosso tema específico de investigação (formação experiencial) e outros novos que possam surgir.

Para o processo de coleta de dados, optamos, primeiramente, por realizar uma análise documental em relação às Diretrizes - Emendas Parlamentares - do PELC e do Projeto básico do PELC/UFSM. Também realizamos uma revisão bibliográfica a respeito de estudos sobre o lazer (especial atenção para a formação e atuação no lazer), sobre o Programa, que tivessem como eixo central o processo formativo dos educadores sociais $^{7}$; e um olhar sobre algumas pesquisas a respeito do tema formação experiencial, com destaque para Josso (2002) e, aproximando-se da área da educação física, os estudos de Figueiredo, Z. C. C (2004, 2009 e 2010).

Em um segundo momento, aplicamos um questionário aberto elaborado a partir de um enfoque sobre as experiências dos colaboradores enquanto acadêmicos em formação. De maneira introdutória, exploramos aquelas experiências vividas anteriormente à entrada no PELC e, em seguida, focamos sobre a experiência do Programa em si.

\footnotetext{
${ }^{7}$ Destacamos as dissertações de mestrado de Ewerton (2010) e Tondin (2011).
} 
Finalizada a realização dos questionários, realizamos um agrupamento das respostas a partir do exposto pelos colaboradores. Dessa forma, emergiram categorias de análise que facilitaram nossas interpretações, bem como a discussão teórica com a literatura revisada para este estudo. Chegamos a essa categorização a partir dos posicionamentos, críticas e ideias principais colocadas pelos colaboradores que foram identificadas a partir de sucessivas leituras das informações coletadas.

Nosso grupo de educadores sociais participantes do estudo compreendia um total de oito sujeitos, todos sendo acadêmicos dos cursos de Educação Física bacharelado ou licenciatura do CEFD/UFSM. Estabelecemos como critério de seleção destes colaboradores um tempo mínimo de atuação no PELC de dois semestres (um ano). Consideramos esse tempo de envolvimento como um período significativo, tanto pela sua amplitude como pelas possibilidades diversas de atuação realizadas. Essas possibilidades diziam respeito ao trabalho cotidiano nas comunidades e os próprios processos formativos do Programa. Com o intuito de facilitar a visualização das respostas dos educadores sociais, colaboradores deste estudo, atribuímos numerações a cada um. Desse modo, estão nomeados como C1, C2, C3 e assim sucessivamente até o C8.

Salientamos ainda que o questionário foi aplicado pessoalmente através de agendamento prévio com os colaboradores em local e horário adequados aos mesmos. Com esse procedimento, buscamos assegurar uma coleta consistente evitando possíveis perdas de amostra por não devolução dos questionários preenchidos. Antes dos procedimentos de coleta, os colaboradores foram devidamente informados e esclarecidos sobre o conteúdo e os usos das informações obtidas, assim como sobre o 
sigilo em relação a suas identidades. Esse processo foi formalizado através do Termo de Consentimento Livre e Esclarecido ${ }^{8}$.

\section{Interpretação dos resultados}

Apresentamos nossas interpretações a partir da identificação de duas principais categorias: a primeira intitulada "Experiências anteriores ao PELC", referindo-se ao percurso acadêmico dos colaboradores; e a segunda "Experiência no PELC". Dentro dessa segunda categoria, ainda nomeamos mais duas subcategorias: a primeira intitulada "Experiência como um processo" e a segunda como "Formação experiencial do educador social de esporte e lazer".

De maneira introdutória e com o intuito de explorar o que os colaboradores já haviam vivido enquanto experiências (Experiências anteriores), constatamos que todos subentendem o termo "experiência" como referência as suas atuações em projetos e atividades de caráter extensionista unicamente. Em nenhum momento, o envolvimento com outras atividades (grupos de estudo e pesquisa, monitoria de disciplinas, atividades de intercâmbio, etc) foram citadas.

Essas atividades de caráter extensionista são compreendidas como complementares a graduação. Desse modo, parecem assumir um papel coadjuvante nesse processo formativo, quando o protagonismo é realizado pelas disciplinas do Curso de graduação. Entretanto, esse protagonismo parece inverter-se em alguns momentos quando alguns aspectos que caracterizam os projetos de extensão são entendidos como mais qualitativos do que aqueles vividos ao longo da graduação, como, por exemplo, a proximidade das realidades sociais e dos momentos práticos de ensino frente a aluno.

\footnotetext{
${ }^{8}$ O estudo foi aprovado pelo Comitê de Ética da Universidade Federal de Santa Maria, em reunião realizada no dia 22/11/2011 sob certificado de apresentação para apreciação ética de número 0273.0.243.000-11.
} 
A experiência nesses projetos, por remeterem-se apenas a ações de caráter prático e de intervenções pedagógicas, denuncia também a existência visível de uma relação dicotômica, na qual os acadêmicos aprendem a teoria nas disciplinas da graduação e aplicam esses conhecimentos em suas intervenções nas atividades de extensão, caracterizando-as como sendo essas as suas experiências, ou seja, as "práticas".

Dentro da segunda categoria (Experiência no PELC), focamos nossa análise sobre as experiências do Programa especialmente. Entretanto, temos o entendimento de que, concretamente, os colaboradores vivem um processo no qual não seja possível separar essa experiência daquelas vividas anteriormente. A característica subjetiva e sempre processual da própria experiência, de uma maneira mais globalizadora, nos atenta para esse cuidado.

Nessa perspectiva, a própria trajetória da maioria dos colaboradores aponta para intervenções práticas nos mais variados espaços, tanto acadêmicos como não acadêmicos; inclusive em PELCs anteriores. O que fica claro é que eles consideram essas atuações como processos de aprendizagens que se dão ao longo do tempo, e por estarem diretamente relacionados a ele, assim como terem características de “incertezas”, não apresentam por si só "receitas" de como podem ou não ocorrer; o que se aprende, como se percebem, entre outros fatores.

Em relação a isso, Isayama (2009) destaca que o processo de ação/reflexão/ação é fundamental para que os profissionais do lazer, nesse caso, os educadores sociais, tornem-se pesquisadores de suas próprias práticas, promovendo uma constante interação entre teoria e prática. A busca dessas "receitas", em especial de atividades práticas, anseia por um número bastante variado de modelos e alternativas que acabam por 
reforçar a lógica de uma formação pautada pelo conhecimento técnico (ISAYAMA, 2011).

Nesse viés, quando Ewerton (2010) trata dos limites da realidade formativa do próprio PELC, alerta para uma aparente dificuldade no exercício permanente desse processo de ação/reflexão/ação, citado por Isayama (2009). Segundo a autora, por vezes, os educadores ainda esperam fórmulas prontas de atividades e propostas pedagógicas, como se estas não precisassem ser contextualizadas na situação e realidade em que serão realizadas.

Na perspectiva experiencial, o que se pode perceber ao longo da atuação é o que acontece no dia a dia, no que se pode atribuir sentidos e significados ao passo que se vai construindo saberes do que está sendo vivido. A exemplo disso, poderíamos citar essa construção "a partir de erros cometidos em aula" (C7), na elaboração de "espaços para relacionar conteúdos" (C2), na relação professor-aluno como o "trato pedagógico e a afetividade que acontece nesse processo" (C4) ou "na escolha de um melhor método de trabalho" (C8).

Mais uma vez, destacamos a característica de inacabamento e continuidade do processo experiencial, como já elucidado em Josso (2002). Mesmo que tenhamos a consciência de que possuímos nossos conhecimentos prévios, aprendemos com a experiência a cada dia a partir de problemáticas que ocorrem durante as intervenções,

[...] seja um questionamento de um aluno ou uma nova situação que nos faz pensar a respeito, mas haverá colaboração na formação do indivíduo se ele refletir a respeito dos fatos ocorridos e procurar uma solução para os problemas sempre procurando melhorar a cada dia $(\mathrm{C} 1)$.

Nesse depoimento, por exemplo, encontramos explícita a necessidade da reflexão como primordial para o processo formativo. Essa necessidade não é nenhuma novidade nas pesquisas sobre formação profissional, sobretudo de educadores sociais, 
professores, pedagogos e profissionais da educação ligados ao ensino. Nossa inquietação não está diretamente ligada à ocorrência desse processo reflexivo na e sobre a prática, mas sim na maneira como este parece acontecer no PELC.

Ao encontro das considerações de Josso (2002), os sujeitos transformam uma sucessão de vivências em experiência a partir do momento que buscam lançar novos olhares sobre o que está se passando. O trabalho reflexivo assume esse papel de transformação quando "aprender pela experiência é ser capaz de resolver problemas dos quais se pode ignorar que tenham formulação e soluções teóricas" (JOSSO, 2002, p. 39). Desse modo, torna-se importante destacar que o processo de aprendizagem deve ser sempre acompanhado de simbolizações.

Nossa consideração sobre a formação experiencial como uma possibilidade evidencia uma perspectiva que pode colaborar para a formação geral dos educadores para o trabalho com o lazer, em especial no PELC. Não queremos com isso atribuir à experiência uma noção de totalidade, ou seja, uma importância formativa que possa se sobressair a outros saberes necessários para a formação de educadores sociais.

Sobre esse cuidado, Pinto (2001) deixa bastante clara a noção de que somente a experiência não garante uma formação sólida para o trabalho com o lazer. Para a autora, não se pode pensar que a educação para e pelo lazer ocorre somente na prática cotidiana, variando entre o errar e o acertar, pois "o saber experiencial precisa ser alimentado com outros saberes, que podem servir de apoio para novas reinvenções e de trocas de experiências que fortalecem lideranças e equipes interdisciplinares (PINTO, 2001, p. 68). Desse modo, o interessante está na ação do pensar sobre a prática de modo que não haja uma supervalorização da mesma, já que essa perspectiva precisa ir ao encontro da práxis consciente (ISAYAMA, 2011) . 
Outro ponto a ser destacado são as preocupações, por parte dos educadores sociais do PELC, sobre as práticas pedagógicas desenvolvidas em aula e o processo de inserção dos mesmos nas comunidades. Esses dois fatores principais acontecem desde a maneira como planejar e avaliar as aulas e as ações até a aceitação da proposta de trabalho nas comunidades. Desse modo, o diálogo com os líderes comunitários, o trato e respeito com as diversidades étnicas, religiosas e sociais dos alunos e os desafios do trabalho com a intergeracionalidade são exemplos de fatores que podem desencadear nos educadores sociais a necessidade de intensa reflexão em relação ao papel que os mesmos exercem ao longo desse processo.

O processo reflexivo e também de tomada de consciência frente, principalmente, a essas situações, se desenvolve tanto no dia a dia das aulas (curto prazo) como após uma sucessão de encontros e ações (longo prazo) a partir do que as próprias situações vão-se demonstrando e sendo percebidas pelos educadores. Nesse perspectiva é que encontramos aproximações com a experiência formadora, no sentido desses educadores estarem em constante processo reflexivo em relação às ações desenvolvidas na práxis das intervenções.

Evidenciamos aí, em uma perspectiva de formação experiencial, ações desenvolvidas pelos educadores que, mesmo tratando-se de atividades conscientes e dotadas de intencionalidade, desencadeiam aprendizagens que não são previsíveis nesse processo, colocando o aprendente (educador social) em interações consigo mesmo e também com os outros (JOSSO, 2002).

A partir dessas interações, constatamos que há a formulação de um perfil deste educador social, assim como do papel que exerce quando inserido nas comunidades. Alguns colaboradores descrevem que, ao atuarem no Programa, vivem verdadeiramente 
esse processo, no sentido de que se inserem profundamente nos espaços de discussão das comunidades. Esse "viver" é definido por uma das colaboradoras (C2) como o sentimento de importância dado a ela por parte da comunidade, percebido pelo reconhecimento de seu trabalho, para além de uma intervenção assistencialista. Ao defender esse posicionamento, a mesma descreve:

[...] pude não somente atuar na realidade de comunidades carentes, como a em que vivo, mas também perceber como a atuação do PELC pode mudar a realidade, não que iremos salvar o mundo, mas ampliamos a visão das pessoas, nem que seja só em relação a elas próprias que valorizam-se mais e passam a cuidar mais de si mesmas e da comunidade onde vivem $(\mathrm{C} 2)$.

Esse sentimento exposto pela colaboradora pode ser compreendido pela relação de proximidade que a mesma estabelecia com as comunidades onde atuava. Sobre isso, Isayama (2011) descreve que a intervenção do profissional não é uma prática desinteressada ou desconectada de uma dimensão política. Essa consciência de pertencimento e envolvimento com uma determinada realidade de trabalho reflete que a ação pedagógica poderá ser mais efetiva quanto mais estreita for a relação estabelecida com as comunidades (ISAYAMA, 2011).

Nessa lógica, os educadores sociais buscam a superação dessa relação de dependência com as ações do PELC, enquanto uma ação que integra uma política governamental. Para isso, é preciso que os mesmos sejam os mediadores dos processos de construção do conhecimento, visando a emancipação das pessoas enquanto sujeitos sociais. Por esse objetivo mais abrangente, os educadores sociais do PELC devem instigar e mediar as discussões que são construídas em conjunto com os alunos, líderes comunitários e outros sujeitos representativos de cada localidade (professores de escolas, agentes de saúde, assistentes sociais, etc). A atuação visa não somente a emancipação cidadã no nível da tomada de consciência, como também do incentivo a busca pela resolução e amenização de problemas sociais que são concretos no cotidiano 
das comunidades periféricas principalmente, como a falta de saneamento básico, más condições das escoas, postos de saúde, transporte coletivo, etc, tendo o direito de acesso ao lazer como ponto de partida para essas e outras lutas.

Essa compreensão se faz necessária e parece clara para alguns educadores sociais, quando percebem que o lazer não pode ser entendido em si mesmo, mas sim como um componente da cultura construída historicamente em nossa sociedade (MARCELINO, 1995). Essa consideração para Marcelino (1995), dentro de uma especificidade concreta do lazer, precisa estar clara para que os educadores tratem o lazer como uma questão de cidadania, de participação cultural e de reivindicação social. Dessa forma, os educadores precisam compreender "a participação cultural como uma das bases para a renovação democrática e humanista da cultura e da sociedade, tendo em vista não só a instauração de uma nova ordem social, mas de uma nova cultura" (MARCELINO, 1995, p. 17).

Esse "emancipar" que os educadores buscam, na realidade, é uma construção sempre coletiva, na qual os educadores criam espaços de intervenção em suas aulas, para, a partir dali, ampliar os debates em relação as mais diversas demandas comunitárias. A caracterização coletiva dessa construção evidencia-se pelo fato de que a atuação dos educadores não pode se dar de maneira alguma de forma impositiva, pois, a partir daí, se estaria guiando o caminho das ações, tirando o protagonismo que deve ser da comunidade. Desse modo, poderia-se dizer que o objetivo mais amplo e, talvez utópico, do PELC, tanto no que se refere aos seus documentos como nas suas ações práticas, é de gerir mecanismos que contribuam para o processo de auto-organização comunitária, instigando-a a fazer por si a partir de processos de auto mobilização. 
Frente a essas considerações, compreendemos que, a partir da formação experiencial dos educadores, formam-se identidades desse sujeito ao estar inserido nas comunidades. Segundo Figueiredo, Z. C. C (2010, p. 156), essas experiências que são consideradas formadoras podem funcionar

[...] como elementos-chave na constituição das identidades construídas nessa trajetória de formação, assumindo um caráter provisório, inacabado, instável. Nesse caso, é importante considerar que a incidência das experiências nas mudanças identitárias e nas subjetivações pode ser, ora mais, ora menos significativa.

Nossa suspeita sobre a construção dessa identidade do educador social do PELC vai ao encontro da consideração de Tondin (2011) quando destaca que o educador deve compreender o seu papel social e ter em mente que o diferencial dele em relação a outros de outras áreas na relação estabelecida com os alunos é apenas o conteúdo. Por isso, compreendemos que o educador social do PELC assume essa identidade de mediador dos processos de construção do conhecimento, junto à comunidade tendo as atividades de lazer como ponto de partida, como já descrito anteriormente nesse trabalho, mas, sobretudo, como um meio importante para a busca de objetivos mais amplos.

\section{Considerações finais}

Consideramos, ao término desse trabalho, a identificação de alguns indícios que consolidam nossa suspeita inicial em relação ao PELC/UFSM. Essa suspeita diz respeito à consideração do Programa não somente como um espaço de intervenção, mas também como um espaço formativo que provoca repercussões sobre a formação inicial dos acadêmicos que nele atuam.

As experiências realizadas ao longo desse processo de atuação evidenciam repercussões para uma formação globalizadora, que não restringe-se apenas aos cursos 
de formação do Programa, pois busca nas intervenções, aprendizagens construtivas do "ser educador social de esporte e lazer". Essa concepção parece clara quando identificamos a construção de um perfil e de identidades na maioria dos educadores investigados durante esse período de atuação. Desse modo, compreendemos que esses educadores identificam-se, principalmente, enquanto mediadores do processo de construção do conhecimento junto à comunidade, no qual o trabalho com as práticas de lazer é o ponto central que possibilita essa mediação.

Entendemos que o trabalho com essas práticas, as quais nos referimos, as coloca ao mesmo tempo como conteúdo e meio. Conteúdo, porque os educadores sociais buscam democratizar o acesso às práticas de lazer, por meio do esporte, dos jogos, da dança, da luta, das artes, etc, sempre com um caráter lúdico e inclusivo. E como meio, porque se utilizam dessas práticas e momentos de lazer para construir discussões que vão além da simples prática de atividades. Dessa forma, as discussões vão desde o próprio lazer enquanto direito dos cidadãos, até outras questões e demandas comunitárias, como já foi mencionado nesse estudo, no que diz respeito às condições de habitação, saúde, educação, entre outras.

Notamos nessa tomada de consciência da maioria dos educadores sociais investigados a apropriação do papel educacional que os mesmos possuem quando inseridos nas comunidades. A partir disso, compreendemos que existem aproximações desse papel com a própria docência, para a qual os educadores (ao menos os acadêmicos do Curso de Licenciatura em Ed. Física do CEFD/UFSM) estão sendo formados ao longo da graduação. Essa relação de aproximação parece existir quando as ações desenvolvidas nessa experiência parecem ser semelhantes àquelas realizadas na escola, 
por exemplo, onde o professor também ocupa um papel de mediação da produção do conhecimento, na busca pela emancipação de seus alunos.

Entretanto, torna-se importante salientar que, por mais que tenhamos constatado essas repercussões para a formação experiencial dos educadores sociais (perfil, identidade e papéis dos educadores), devemos atentar para os "níveis" de incidência nesse processo. Esses níveis aos quais nos referimos estão diretamente relacionados com a intensidade pela qual as experiências podem incidir ou não sobre o processo formativo dos sujeitos. Dessa forma, queremos elucidar que, a partir das contribuições de alguns colaboradores, pouco tivemos para analisar e realizar reflexões, pois, para estes, a atuação no Programa foi, na realidade, uma participação como outra qualquer em uma atividade extracurricular. A consideração da tradicional "prática pela prática" ou da supervalorização dos saberes experienciais em detrimento de outros saberes necessários para atuação no PELC nos dão esse indício de uma repercussão formativa limitada para alguns educadores.

O que nos fez acreditar em nossas considerações prévias em relação ao PELC como um espaço formativo foram as contribuições da maioria dos colaboradores, que apresentavam-se bem consolidadas, de maneira crítica e clara quanto as ideias e posicionamentos descritos.

Outro ponto para ser destacado é a consideração de alguns limites nas ações do PELC/UFSM. Ao analisarmos uma experiência até certo ponto "positiva" do PELC em Santa Maria, salientamos os avanços dessa atuação dos educadores no Programa, mas com o cuidado de trata-la como uma possibilidade. Esse cuidado torna-se necessário frente às limitações do Programa enquanto uma política de governo de tipo finalístico. Desse modo, sendo as ações do Programa temporárias, acreditamos ser relevante 
descrever o quanto ainda há uma relação de dependência entre a organização comunitária e as ações do PELC.

Essa consideração justifica-se porque, por mais que o Programa tenha como objetivo desenvolver a autonomia na comunidade, ou seja, incentivar os membros comunitários a reivindicarem seus direitos, em especial do acesso ao lazer, essa autonomia parece estar sempre mediada e direcionada pelo PELC. Quando a vigência do Programa chega ao fim, pouco se avança em algumas comunidades nessa discussão, pois os educadores não estão mais presentes nas comunidades realizando uma mediação dessas discussões que, por vezes, assume características de uma liderança nas lutas sociais. Liderança esta que deveria pertencer à comunidade.

Por fim, salientados nossos avanços e registradas nossas limitações investigativas, acreditamos que essa atuação no PELC/UFSM pode ser configurada como uma experiência formadora. Os educadores sociais, em sua maioria, estiveram envolvidos com uma diversidade de ações que foram percebidas e sintetizadas em suas respostas e que confirmaram conhecimentos acerca do Programa e também do papel educativo que esses educadores ocupam.

\section{REFERÊNCIAS}

ALMEIDA, L.; FENSTERSEIFER, P. E. O lugar da experiência no âmbito da Educação Física. Revista Movimento, Porto Alegre, v. 17, n. 04, p. 247-263, out/dez., 2011. BRASIL. Ministério do Esporte. Disponível em: http://www.esporte.gov.br/sndel/esporteLazer/default.jsp Acesso em: 11 jul. 2011.

BRASIL. Ministério do Esporte. Secretária Nacional de Esporte, Educação, Lazer e Inclusão Social. Departamento de Formulação de Políticas e Estratégias. CoordenaçãoGeral de Esporte e Lazer. Diretrizes - Emendas Parlamentares - do Programa Esporte e Lazer da Cidade. Brasília, 2012.

BRASIL. Política Nacional do Esporte. Resolução $n^{0}$ 05/Conselho Nacional do Esporte. ME. Brasília, 2005. 
BRASIL. Projeto Básico do Programa Esporte e Lazer da Cidade da Universidade Federal de Santa Maria (PELC/UFSM), Santa Maria, 2010.

EWERTON, A. N. Análise da formação profissional do Programa Esporte e Lazer da Cidade (PELC): o olhar dos agentes sociais. 2010, Dissertação (Mestrado em Lazer) - Escola de Educação Física, Fisioterapia e Terapia Ocupacional, Universidade Federal de Minas Gerais, Belo Horizonte, 2010.

FIGUEIREDO, P. O. F. N. Política e Formação: O Programa Esporte e Lazer da Cidade no Distrito Federal e Entorno. 2009. Dissertação (Mestrado em Educação Física) - Faculdade de Educação Física, Universidade de Brasília, Brasília, 2009.

FIGUEIREDO, Z. C. C. Experiências Sociais no Processo de Formação Docente em Educação Física. 2004. Tese. (Doutorado em Educação) - Faculdade de Educação, Universidade Federal de Minas Gerais, Belo Horizonte, 2004.

FIGUEIREDO, Z. C. C. Uma Experiência de Formação de Professores de Educação Física na Perspectiva do Formar-se Professor. Revista Pensar a Prática, Goiânia, v. 12, n. 03, p. 1-11, set/dez.,2009.

FIGUEIREDO, Z. C. C. Experiências profissionais, identidades e formação docente em educação física. Revista Portuguesa de Educação, Lisboa, v. 23, n. 02, p. 153-171, 2010 .

GOMES, C. L.; MELO, V. A. Lazer no Brasil: trajetória de estudos, possibilidades de pesquisa. Movimento, Porto Alegre, v. 9, n. 1, p. 23-44, jan./abr. 2003.

ISAYAMA, H. F. Atuação do profissional de educação física no âmbito do lazer: a perspectiva da animação cultural. Motriz, Rio Claro, v. 15, n. 2, p. 407-413, abr./jun. 2009.

ISAYAMA, H. F. Sobre a formação de profissionais para a atuação no mercado de trabalho em lazer. In: PINTO, L. M. S. M. (Org.). Lazer, turismo e hospitalidade: desafios para as cidades-sede e subsedes de megaeventos esportivos. 2. ed. Brasília: Ideal, 2011. p. 93-97.

JOSSO, M. Experiências de vida e formação. Lisboa: Educa, 2002.

MARCELINO, N. C. A ação profissional no lazer, sua especificidade e seu caráter interdisciplinar. In: MARCELINO, N. C. (Org.). Lazer: formação e atuação profissional. Campinas: Papirus, 1995. p. 13-22.

MASCARENHAS, F. "Lazerania" também é conquista: tendências e desafios na era do mercado. Movimento, Porto Alegre, v. 10, n. 2, p.73-90, mai./ago. 2004.

MASCARENHAS, F. Exclusão social clube: problema para as políticas públicas e gestão em esporte e lazer. In: CONGRESSO BRASILEIRO DE CIÊNCIAS DO ESPORTE, 14, 2005, Porto Alegre. Anais... Porto Alegre: CBCE, 2005. Disponível em http://www.cbce.org.br/br/anais/conbrace2005.pdf. Acesso em: 20 jan. 2014. 
MOITA, M. C. Percursos de formação e trans-formação. In: NÓVOA, A. (Org.). Vidas de professores. Porto: Porto Editora, 1992. p. 111-140.

NÓVOA, A. Os professores e as histórias de suas vidas. In: NÓVOA. A. (Org.). Vidas de professores. Porto: Porto Editora, 1992. p. 11-30.

PINTO, L. M. S. M. Formação de educadores e educadoras para o lazer: saberes e competências. Revista Brasileira de Ciências do Esporte, v. 22, n. 3, p. 53-71, maio 2001 .

SUASSUNA, D. M. F. A. O Programa Esporte e Lazer da Cidade: A política de formação para o trabalho e o papel dos agentes sociais. In: CONGRESSO BRASILEIRO DE CIÊNCIAS DO ESPORTE, 16 [E] CONGRESSO INTERNACIONAL DE CIÊNCIAS DO ESPORTE, 3, 2009, Salvador. Anais... Salvador: CBCE, 2007. p. 1-11.

TAFFAREL, C. Z. A prática pedagógica e a inclusão social: um desafio da Educação Física, $2009 . \quad$ Disponível em http://www.rascunhodigital.faced.ufba.br/ver.php?idtexto=595 . Acesso em: 20 jan. 2014.

TARDIF, M. Saberes profissionais dos professores e conhecimentos universitários: elementos para uma epistemologia da prática profissional dos professores e suas conseqüências em relação à formação para o magistério. Revista Brasileira de Educação, Campinas, n. 13, p. 5-24, jan/abr., 2000.

THOMASSIM, L. E. C. Os sentidos da exclusão social na bibliografia da Educação Física brasileira. Movimento, Porto Alegre, v. 13, n. 1, p. 151-178, jan./abr. 2007.

TONDIN, G. A formação dos educadores sociais de esporte e lazer no Programa Esporte e Lazer da Cidade de Porto Alegre - RS. In: CONGRESSO SULBRASILIERO DE CIÊNCIAS DO ESPORTE, 5, 2010, Itajaí. Anais... Itajaí: RBCE, 2010. Disponível em:

http://www.rbceonline.org.br/congressos/index.php/vcsbce/vcsbce/schedConf/presentati ons. Acesso em: 20 de set. 2010.

TONDIN, G. A formação dos educadores sociais de esporte e lazer no Programa Esporte e Lazer da Cidade - PELC - em Porto Alegre. 2011. Dissertação (Mestrado em Ciências do Movimento Humano) - Escola de Educação Física, Universidade Federal do Rio Grande do Sul, Porto Alegre, 2011.

TRIVIÑOS, A. N. S. Introdução à pesquisa em ciências sociais - pesquisa qualitativa em educação. São Paulo: Atlas, 1987. 175 p.

\section{Endereço dos Autores:}

Felipe Barroso de Castro

Rua Arcângelo Favarin, 15 
Bairro Km 3, Santa Maria - RS

CEP: 97095-050

Endereço Eletrônico: felipecastro99@yahoo.com.br

Maria Cecília Camargo Günther

Rua Alfredo Tonetto, 314

Bairro Camobi, Santa Maria - RS

CEP: 97110-802

Endereço Eletrônico: mceciliacg6@hotmail.com

Elisandro Schultz Wittizorecki

Rua Argemiro Dornelles, 69

Bairro Nossa Senhora de Fátima, Guaíba - RS

CEP: 92500-000

Endereço Eletrônico: elisandro.wittizorecki@ufrgs.br 